\title{
Toxoplasma gondii ROP16 kinase silences the cyclin B1 gene promoter by hijacking host cell UHRF1-dependent epigenetic pathways
}

\author{
Marcela Sabou ${ }^{1,2}$. Cécile Doderer-Lang ${ }^{1} \cdot$ Caroline Leyer $^{1} \cdot$ Ana Konjic $^{1}$ - Sophie Kubina ${ }^{1} \cdot$ Sarah Lennon $^{3}$. \\ Olivier Rohr ${ }^{1}$ - Stéphane Viville ${ }^{1}$ - Sarah Cianférani ${ }^{3} \cdot$ Ermanno Candolfi, $^{1,2}$. Alexander W. Pfaff ${ }^{1,2}$ (I) Julie Brunet ${ }^{1,2}$
}

Received: 5 April 2019 / Revised: 12 July 2019 / Accepted: 5 August 2019 / Published online: 6 September 2019

(c) The Author(s) 2019

\begin{abstract}
Toxoplasmosis, caused by the apicomplexan parasite Toxoplasma gondii, is one of the most common infections in the world due to the lifelong persistence of this parasite in a latent stage. This parasite hijacks host signaling pathways through epigenetic mechanisms which converge on key nuclear proteins. Here, we report a new parasite persistence strategy involving T. gondii rhoptry protein ROP16 secreted early during invasion, which targets the transcription factor UHRF1 (ubiquitinlike containing PHD and RING fingers domain 1), and leads to host cell cycle arrest. This is mediated by DNMT activity and chromatin remodeling at the cyclin $B 1$ gene promoter through recruitment of phosphorylated UHRF1 associated with a repressive multienzymatic protein complex. This leads to deacetylation and methylation of histone $\mathrm{H} 3$ surrounding the cyclin B1 promoter to epigenetically silence its transcriptional activity. Moreover, T. gondii infection causes DNA hypermethylation in its host cell, by upregulation of DNMTs. ROP16 is already known to activate and phosphorylate protective immunity transcription factors such as STAT 3/6/5 and modulate host signaling pathways in a strain-dependent manner. Like in the case of STAT6, the strain-dependent effects of ROP16 on UHRF1 are dependent on a single amino-acid polymorphism in ROP16. This study demonstrates that Toxoplasma hijacks a new epigenetic initiator, UHRF1, through an early event initiated by the ROP16 parasite kinase.
\end{abstract}

Keywords Toxoplasma gondii $\cdot \mathrm{UHFR} 1 \cdot \mathrm{ROP} 16 \cdot$ Cyclin B1 $\cdot$ DNMT $\cdot$ Epigenetic regulation

Electronic supplementary material The online version of this article (https://doi.org/10.1007/s00018-019-03267-2) contains supplementary material, which is available to authorized users.

Ermanno Candolfi and Alexander W. Pfaff contributed equally to the manuscript.

Alexander W. Pfaff

pfaff@unistra.fr

1 Institut de Parasitologie et de Pathologie Tropicale de Strasbourg, «Dynamics of Host-Pathogen Interactions » EA 7292, Fédération de Médecine Translationelle Université de Strasbourg, Strasbourg, France

2 Service de Parasitologie et Mycologie Médicale, Hôpitaux Universitaires de Strasbourg, Centre National de Référence de la Toxoplasmose, Pôle Sérologie, Strasbourg, France

3 Laboratoire de Spectrométrie de Masse BioOrganique (LSMBO), Université de Strasbourg, IPHC, CNRS, UMR7178, Strasbourg, France

\section{Introduction}

Toxoplasmosis, caused by the intracellular apicomplexan parasite Toxoplasma gondii is one of the most common infections in the world, leading to a lifelong latent infection due to the persistence of the parasites within cysts in specific host organs like the brain, the muscles or the eye [1]. While generally asymptomatic, the infection can be severe in case of primary infection during pregnancy or reactivation in immunosuppressed individuals. There is neither efficient treatment against the latent parasite forms nor a vaccine.

A particularity of $T$. gondii is the existence of numerous strains with different geographical distribution and strikingly different virulence. Originally, three major lineages had been described in Europe and North America, with type I strains being highly virulent in mouse infections, while type II and III strains showed moderate virulence [2]. More recently, genetic examination of 958 strains collected from around the world classified them into 15 haplogroups within 6 major clades [3]. 
To achieve intracellular persistence, $T$. gondii modulates and hijacks host cell pathways involved in various processes such as inflammation, apoptosis, metabolism, and cell growth [4]. This prevents infected cells from apoptosis and subverts the host's immune system [5, 6]. The parasite manipulates the host cell signaling pathways by secreting kinases and phosphatases, of which some infiltrate the host cell nucleus and modulate gene expression activity. ROP16, a $T$. gondii protein kinase secreted during early stages of invasion, has been described to activate and phosphorylate immune-related transcription factors such as STAT 3/5/6 and modulate host signaling pathways in a strain-dependent manner [7-10]. Our recent results in a mouse model of ocular toxoplasmosis showed the capacity of ROP16 to influence cytokine expression and parasite control in vivo [11], demonstrating its biological importance and need to elucidate its effects on a cellular level. Toxoplasma straindependent effects on host factors have also been reported for ROP18, GRA15 and other effectors [8, 12]. For STAT3, the strain dependence of ROP16 action is determined by a single amino-acid polymorphism [13].

These changes in host genome activity imply modifying the epigenome of the host cell [14]. Until now, only few Toxoplasma proteins have been described as able to trigger the initial epigenetic signal: the rhoptry protein ROP18, as well as the dense granule proteins GRA15, GRA16 and probably GRA24 [4, 15-17]. Toxoplasma is able to imprint epigenetic marks on the host cell genome. Thus, the parasite prevents histone $\mathrm{H} 3$ phosphorylation and acetylation at the TNFA and ILIO promoters [18, 19]. Similarly, severely impaired histone acetylation at IFN- $\gamma$-regulated promoters during infection, and a parasite-mediated defect in the recruitment of chromatin remodeling complexes have been reported $[14,20]$. Decreased promoter methylation, through DNA methyltransferase activity has been shown to increase gene expression of neurons in Toxoplasma-infected rats [21].

CpG methylation by the DNA methyltransferases, DNMT1 and DNMT3a/b, and histone modifications are two major components of the epigenetic regulation. Transition from an active to an inactive state of transcription requires a series of coordinated modifications on histone residues. They are catalyzed by specific enzymes, but even their intrinsic affinity for their substrates is insufficient to explain their high site specificity in inducing chromatin modifications. UHRF1 (ubiquitin-like containing PHD and RING finger domain 1) plays a major role in the reading and inheritance of epigenetic code due to its ability to recruit effectors catalyzing these marks [22-25]. UHRF1 is an important epigenetic regulator with different structural domains: an N-terminal ubiquitin-like (UbL) domain, a tandem tudor (TTD) domain, a plant homeodomain (PHD), a SET and RING (really interesting new gene)-associated (SRA) domain. These domains are associated with binding to methylated DNA (SRA domain), histones (TTD and PHD domains) and epigenetic effectors (SRA, TTD, PHD domains) [24]. UHRF1 and the associated proteins play a central role in epigenetic modifications such as DNA methylation and histone modifications. Indeed, UHRF1 is associated with maintenance of DNA methylation patterns by recruiting DNMT1 to hemi-methylated $\mathrm{CpG}$, and histone modifications by interacting with HDAC1 and DNMT1 [23, $25,26]$. UHRF1 coordinates epigenetic silencing of tumor suppressor genes and plays a key role in cell cycle, epigenetic regulation in the development and progression of cancers and metastasis [24, 27].

We have previously shown that both cyclin B1 mRNA and protein are downregulated in $T$. gondii-infected cells, resulting in dissociation of the cyclin $\mathrm{B} 1 / \mathrm{Cdk} 1$ complex, which is necessary for the G2/M transition. We also found that infection-induced upregulation of UHRF1 expression is responsible for the host cell arrest at the G2 phase and is essential for parasite proliferation [28]. ROP16 was reported to interact with p53 resulting in G1 cell cycle arrest [29].

Here, we report a new parasite strategy involving ROP16 which targets UHRF1. This event prevents chromatin remodeling at the cyclin $B 1$ gene $(C C N B 1)$ promoter through recruitment of phosphorylated UHRF1 associated to a repressive multienzymatic complex. This leads to deacetylation and methylation of histone $\mathrm{H} 3$ surrounding the $C C N B 1$ promoter to epigenetically silence its transcriptional activity. Moreover, T. gondii infection causes DNA hypermethylation in its host cell by upregulation of DNMTs. This study demonstrates that Toxoplasma hijacks another epigenetic initiator, UHRF1, through an early event initiated by the ROP16 kinase.

\section{Materials and methods}

\section{Cells and parasites}

The human trophoblast cell line BeWo was obtained from the American Type Culture Collection (Mannassas, VA) and cultured in FK12 medium (Fisher Scientific, IllkirchGraffenstaden, France), supplemented with $10 \%$ heat inactivated FCS (Invitrogen, Cergy Pontoise, France), 10 U/ml penicillin, $10 \mu \mathrm{g} / \mathrm{ml}$ streptomycin (Invitrogen). The human astrocytic cell line U-118MG was cultured in DMEM medium (Fisher Scientific), supplemented as above plus $2 \mathrm{mM}$ glutamine. Cell cultures were kept at $37{ }^{\circ} \mathrm{C}, 5 \% \mathrm{CO} 2$ and cell numbers were determined with a Neubauer cell counting chamber using a Trypan blue (Corning, Corning $\mathrm{NY}$ ) exclusion test.

The virulent RH $T$. gondii strain was originally obtained from the French Biological Resource Center Toxoplasma (CRB Toxoplasma; Laboratoire de Parasitologie, CHU 
Reims, France). The RH $\Delta$ ROP16 strain was kindly provided by J. Boothroyd, Stanford University. Preliminary assays showed similar parasite proliferation and UHRF1 regulation of the RH and the RH $\Delta$ KU80 strain, which was used to create the KO strain. RH parasites were thus used as control strain. Tachyzoites were maintained in human THP1 monocyte cultures or by weekly passages in Swiss Webster mice. Before use, they were washed twice in PBS and counted using Trypan blue exclusion test.

To create ROP16 mutant plasmids, the coding region of ROP 16 was amplified by PCR on genomic DNA from the RH, PRU and LEF strains using primers 5'-CGGAATTCA TGAAAGTGACCACGA-3' and 5'-CGCTCTAGACTACAT CCGATGTGAAG - $3^{\prime}$ including the EcoRI and BgIII restriction sites. An amplified fragment of 2124pb was purified and inserted into the cloning vector pGEMT $^{\circledR}$ (Promega) by ligation after A-tailing. PGEMT-ROP 16 was digested by EcoRI and BglII restriction enzymes and cloned in pCDNA3-HA vector (Invitrogen).

The mutant plasmid ROP16 6 Cat, deficient for the kinase catalytic domain was generated using the a site-directed mutagenesis kit (Stratagene, San Diego, USA) on the expression vectors containing the wild-type gene of ROP16 The primers used were sense 5'-GAGTGCCGATCGCTCAGC AAGCCCCTGG-3' and antisense 5'-CCAGGGGCTTGC TGAGCGATCGGCACTC-3'. The mutants L503S for RH and LEF strains and S503L for PRU were likewise generated, using the primers (L503S) sense 5' CCA TTA ATT GAT GGC TCC GCA TCG AAC AGT CTA GTC CAG TC 3'; antisense 5' GAC TGG ACT AGA CTG TTC GAT GCG GAG CCA TCA ATT AAT GG 3' and (S503L) sense 5' CCA TTA ATT GAT GGC TCC CCA TTG AAC AGT CTA GTC CAG TC 3'; antisense 5' GAC TGG ACT AGA CTG TTC AAT GGG GAG CCA TCA ATT AAT GG $3^{\prime}$.

\section{Transfection of host cells and luciferase assays}

The corresponding nucleotides of UHRF1 were cloned into a siRNA expression vector, psiU6BX3, constructed as previously described [30]. A EGFP-siRNA or UHRF1-siRNA (si-3: 2123-2141) plasmid construct was transfected to cells for $24 \mathrm{~h}$ and incubated with $900 \mu \mathrm{g} / \mathrm{ml}$ of G418 for a further $48 \mathrm{~h}$ before infection with $T$. gondii as indicated in the figure legends. Cells were then harvested for Western blotting. pGL3-UHRF1-Luc plasmids were generously donated by M. Unoki, University of Tokyo, Japan. BeWo cells were transfected with plasmids $(2 \mu \mathrm{g} /$ well $)$ for $24 \mathrm{~h}$ with X-tremeGENE ${ }^{\mathrm{TM}}$ (Sigma-Aldrich, Saint-Quentin-Fallavier, France) transfection reagent and infected with $T$. gondii for the indicated times and harvested for luciferase activity measurements with $250 \mu \mathrm{L}$ of Bright-Glo luciferase assay Buffer (Promega, Charbonnières-les-Bains, France). Results are expressed as a ratio of the protein quantification, as our preliminary tests showed that the protein masses of the parasites are negligible compared to the cell protein contents.

\section{Chemicals and antibodies}

Polyclonal anti-T. gondii antibody was raised in New Zealand rabbits by several injections of $50 \mu \mathrm{g}$ of soluble $T$. gondii antigen suspended in Freund's incomplete adjuvant. The $\mathrm{IgG}$ fraction of this serum was purified by chromatography on DEAE Trisacryl (1 M) and tested by ELISA. The mouse monoclonal antibody against UHRF1 (clone 1RC1C-10) was engineered as described elsewhere [28]. The anti-cyclin B1, anti-p-Ser and anti-actin mouse monoclonal antibodies or anti-DNMT1 rabbit polyclonal antibody were obtained from Santa Cruz Biotechnology (Santa Cruz, CA).

Alexa Fluor 488 goat anti-rabbit IgG was obtained from Invitrogen (Carlsbad, CA).

Goat $\mathrm{F}(\mathrm{ab}$ ') 2 fragment anti-mouse IgG-peroxidase, donkey $\mathrm{F}(\mathrm{ab}$ ')2 fragment anti-rabbit IgG-peroxidase, Tween20 and the protease inhibitor cocktail were purchased from Roche Diagnostics (Basel, Switzerland). G 418 was purchased from Sigma-Aldrich (Saint-Louis, MO).

The ECL detection system was obtained from Amersham Biosciences (GE Healthcare Europe GmbH, Orsay, France). TriReagent was purchased from Molecular Research Center (Cincinnati, $\mathrm{OH}$ ).

\section{Flow cytometry}

BeWo cells were grown in six-well plates (Dutscher, Brumath, France) and infected at sub-confluent conditions with T. gondii for the indicated times at $37{ }^{\circ} \mathrm{C}$. The cells were harvested by trypsinization (Fisher Scientific) and gently washed three times with $1 \mathrm{ml}$ of PBS. Cell suspensions were fixed by incubation for $15 \mathrm{~min}$ on ice in $0.4 \mathrm{ml}$ of $5 \%$ formaldehyde in PBS (v/v), washed with PBS; then resuspended in $1 \mathrm{ml}$ of absolute ethanol and stored at $-20{ }^{\circ} \mathrm{C}$ until use. Infected cells were identified by flow cytometry. Briefly, cells were washed and stained for $45 \mathrm{~min}$ with rabbit anti-T. gondii IgG antibody. Then, samples were washed and incubated with Alexa Fluor 488 goat anti-rabbit for $45 \mathrm{~min}$ and washed again. DNA labeling was obtained by incubation for $2 \mathrm{~h}$ with $50 \mu \mathrm{g} / \mathrm{ml}$ of propidium iodide and $50 \mu \mathrm{g} /$ $\mathrm{ml}$ of RNAse A (Euromedex, Souffelweyersheim, France) at room temperature in the dark. Fluorescence was measured in a FACScan flow cytometer (Becton-Dickinson, Franklin Lakes, NJ) and analyzed with the CellQuest software package.

\section{Western blotting and co-immunoprecipitation}

Whole cell extracts were prepared as described elsewhere [30]. Blots were probed with the indicated antibodies at 
$1 \mu \mathrm{g} / \mathrm{ml}$. For co-immunoprecipitation of UHRF1, infected or uninfected cell extracts were incubated with protein $\mathrm{G}$ beads coupled to anti-UHRF1 monoclonal antibody $(5 \mu \mathrm{g})$ in $1 \mathrm{ml}$ PBS supplemented with protease inhibitors for $2 \mathrm{~h}$ at $4{ }^{\circ} \mathrm{C}$. Beads were washed five times with PBS and bound proteins were removed from the beads, denatured using loading buffer and separated on 10\% SDS-PAGE gels, blotted and finally probed with $1 \mu \mathrm{g} / \mathrm{ml}$ of antibodies. Secondary peroxidase conjugated antibodies were used at $0.16 \mu \mathrm{g} / \mathrm{ml}$. Signals were visualized by chemiluminescence using the ECL detection system.

\section{Proteomics}

Samples were separated on a $10 \%$ SDS-PAGE gel stained with Coomassie blue. After migration, each line was cut every $2 \mathrm{~mm}$ and the gel plugs transferred into a 96-well plate.

In-gel digestion was performed with an automated protein digestion system, a MassPrep Station (Waters, Manchester, U.K.). The gel plugs were washed twice with 50 $\mu \mathrm{L}$ of $25 \mathrm{mM}$ ammonium hydrogen carbonate and $50 \mu \mathrm{L}$ of acetonitrile. The cysteine residues were reduced by addition of $10 \mathrm{mM}$ dithiothreitol at $60{ }^{\circ} \mathrm{C}$ and alkylated by addition of $50 \mu \mathrm{L}$ of $55 \mathrm{mM}$ iodoacetamide. After dehydration with acetonitrile, the proteins were cleaved in gel with a $12.5 \mathrm{ng} / \mu \mathrm{L}$ solution of modified porcine trypsin (Promega, Madison, WI) in ammonium hydrogen carbonate $(\approx 15 \mu \mathrm{L})$. The digestion was performed overnight at $37{ }^{\circ} \mathrm{C}$. Tryptic peptides were extracted twice: with $40 \mu \mathrm{L}$ of a 60/40/0.1 $\mathrm{ACN} / \mathrm{H}_{2} \mathrm{O} / \mathrm{HCOOH}$ solution for $1 \mathrm{~h}$ and with $40 \mu \mathrm{L}$ of pure $\mathrm{ACN}$. The collected extracts were pulled and evaporated to $10 \mu \mathrm{L}$ with a vacuum centrifuge (Speedvac ${ }^{\circledR}$, Thermo Savant SPD111 V, Waltham, MA, USA).

For MS analysis, each sample was analyzed on a nanoAcquity $^{\mathrm{TM}}$ (Waters, Manchester, U.K.) coupled to a Synapt G1 (Waters, Manchester, U.K.), which was equipped with a nanoelectrospray ion source. Peptide separation was carried out on a RP-HPLC column C18 $(75 \mu \mathrm{m} \times 200 \mathrm{~mm}$ length nanoAcquity ${ }^{\mathrm{TM} U P L C} \mathrm{C}^{\mathrm{TM}}$, porosity $\left.1.7 \mu \mathrm{m}\right)$. The gradient was performed by a mix of two solvents A $(0.1 \%$ formic acid in water) and B ( $0.1 \%$ formic acid in acetonitrile). Separation was performed at $300 \mathrm{~nL} / \mathrm{min}$ flow rate using a $35 \mathrm{~min}$ gradient from 10 to $40 \% \mathrm{~B}$. The capillary, sample cone and extraction cone voltages were set to $3000 \mathrm{~V}, 35 \mathrm{~V}$ and $40 \mathrm{~V}$, respectively. The temperature of the source was set to $90^{\circ} \mathrm{C}$.

Mass calibration was achieved using the fragmentation of glyco-fibrin peptide over the range 250-2000 Da. Acquisition was performed with the Masslynx software 4.1. (Waters, Manchester, UK). The MS survey scan was acquired on the range $\mathrm{m} / \mathrm{z} 250-1500$ with a scan time of $0.5 \mathrm{~s}$. The five most intense ions of the MS spectra were selected for MS/MS (intensity threshold 20 counts). CID fragmentation was performed using argon as collision gas and with collision energy profile optimized for various mass ranges of precursor ions. The scan range for MS/ MS acquisition was from m/z 50 to $2000 \mathrm{Da}$ with a scan time of $0.8 \mathrm{~s}$. If the intensity of the MS/MS was less than $4500 \mathrm{cps}$, the MS/MS scan lasted $2.3 \mathrm{~s}$. A selected ion is excluded for $4 \mathrm{~s}$ after the selection.

Data collected during a nanoLC-MS/MS analysis were automatically processed and converted into a.pkl file using ProteinLynx Browser 2.3 (Waters, Manchester, U.K.). These files were then submitted to Mascot (Matrix Science, London, U.K.) against a mixed human (Swiss prot, 23/02/2012) and toxo (Toxodb, vr6.3, 22/01/2011) decoy database (88 468 entries). Searches were performed with a tolerance on mass measurement of $15 \mathrm{ppm}$ for the precursor and $0.07 \mathrm{Da}$ on the fragments. Carbamidomethylation of cysteine residues and oxidation of methionine residues were searched as variable modifications. Up to one missed cleavage was allowed.

Scaffold 3.00.03 (Proteome Science, Portland, Oregon) was used for identification validation and false positive rate estimation for protein identification. Selection filters were applied to obtain a false positive rate (FDR) less than $1 \%$. Seven proteins of interest were selected, MS/MS spectra extracted and manually verified. These seven proteins of interest were then validated by immunoprecipitation.

\section{Quantitative PCR and RT-PCR analysis}

Cells were cultured in six-well plates, infected with $T$. gondii for the indicated times and lysed with TriReagent. Total RNA was extracted according to the manufacturer's recommendations. $5 \mu \mathrm{g}$ of RNA were then reverse transcribed using qScript cDNA Synthesis Kit (Quantabio). Primers were used at a final concentration of $0.5 \mu \mathrm{M}$ : glyceraldehyde-3-phosphate dehydrogenase (GAPDH, $137 \mathrm{bp})$ sense 5'-AGC AAT GCC TCC TGC ACC ACC AAC-3'; antisense 5'-CCG GAG GGG CCA TCC ACA GTCT3'; DNMT1 (144 bp) sense 5'- AGGACAGGGGACCCA CGAAA-3'; antisense 5'- ACA CCT CAC AGA CGC CAC AT-3'; UHRF1 (240 bp) sense 5'- GGG GCT ATG AGG ATG ATG TG-3'; antisense 5'-TCT TGC CAC CCT TGA CAT T-3'. Quantification of transcripts was performed by an external standard curve. Real-time PCR was carried out on the CFX Connect ${ }^{\mathrm{TM}}$ Real-Time PCR detection system (Bio-Rad, Marnes la Coquette, France) using the SsoAdvanced $^{\mathrm{TM}}$ Universal SYBR ${ }^{\circledR}$ Green Mix (Bio-Rad). After $30 \mathrm{~s}$ of denaturation at $95^{\circ} \mathrm{C}$, the reaction was cycled 40 times, $10 \mathrm{~s}$ at $95{ }^{\circ} \mathrm{C}, 10 \mathrm{~s}$ at $58^{\circ} \mathrm{C}$ and $30 \mathrm{~s}$ at $72{ }^{\circ} \mathrm{C}$. Product specificity was determined by melting curve analysis. 


\section{Chromatin immunoprecipitation (ChIP) analysis}

Cells were cultured in $10 \mathrm{~cm}$ dishes and then infected with T. gondii for the indicated times. ChIP was performed according to manufacturer's recommendations (ChIPIT Express enzymatic kit, Active Motif, CA, USA). The supernatant containing the sheared chromatin was incubated with anti-UHRF1 or anti-Actin (as negative control) antibody and magnetic beads overnight at $4{ }^{\circ} \mathrm{C}$ on a roller shaker. The beads were washed and incubated with $100 \mu \mathrm{l}$ of elution buffer at $65^{\circ} \mathrm{C}$ for $2.5 \mathrm{~h}$. Cross-linking was reversed by a $1.5 \mathrm{~h}$ incubation with $2 \mu \mathrm{l}$ of proteinase $\mathrm{K}$ at $37{ }^{\circ} \mathrm{C}$. DNA was extracted using the QiaMini Kit (Qiagen). DNA samples from the ChIP experiments were subjected to PCR using CYCLINB1 promoter-specific primers (sense 5'-CGC CAA TGG GAA GGG AGT-3', antisense 5'-CCA CAA GAC GAA GAG GGG C-3') and TaqDNA polymerase (Invitrogen). The reaction contents were heated to $94{ }^{\circ} \mathrm{C}$ for $15 \mathrm{~min}$ for polymerase activation followed by 35 cycles at $94{ }^{\circ} \mathrm{C}$ for $30 \mathrm{~s}, 55^{\circ} \mathrm{C}$ for $30 \mathrm{~s}$, $72{ }^{\circ} \mathrm{C}$ for $30 \mathrm{~s}$ and a final step at $72{ }^{\circ} \mathrm{C}$ for $7 \mathrm{~min}$.

\section{Methylation analysis}

BeWo cells were cultured and infected in six-well plates, as described above. DNA was extracted using QiaMini Kit (Qiagen). Bisulfite conversion was performed using MethylDetector (Active Motif), according to the manufacturer's recommendations. The modified DNA was then subjected to PCR amplifications of the repetitive LINE1 sequence, using either primers specific for the methylated sequence (sense 5'-AAG ATG GTC GAA TAG GAA TAG-3', antisense 5'-CAC TCC CTA ATA AAA TAA ACC-3') or for the unmethylated sequence (sense 5'-AGA TGG TTG AAT AGG AAT AGT-3', antisense 5'-CAC TCC CTA ATA AAA TAA ACC-3'), at an annealing temperature of $55{ }^{\circ} \mathrm{C}$. Cycle numbers were optimized to stop the reaction in the logarithmic phase of amplification. Quantity One 4.6.5 software (Bio-Rad, Philadelphia, PA) was used for measuring the density of PCR bands.

\section{DNMT assay}

BeWo cells were cultured in six-well plates and then infected with $T$. gondii for the indicated times. DNMT activity was performed on $10 \mu \mathrm{g}$ of nuclear extract using DNMT activity (Active Motif), according to manufacturer's recommendations. Absorbances were read at $450 \mathrm{~nm}$. As $T$. gondii was shown not to possess DNMT activity [31], these results fully represent host cell DNMT activity.

\section{Statistical analysis}

Statistical analysis was performed using Student's $t$ test for comparisons between two groups, or one-way ANOVA followed by Dunnett's post-test for comparisons relative to a control group. All tests were performed using GraphPad. A $P$ value below 0.05 was considered statistically significant.

\section{Results}

\section{Activation of UHRF1 promoter and phosphorylation of UHRF1 in T. gondii-infected cells correlate with rhoptry secretion}

We previously reported that UHRF1 expression is rapidly upregulated in $T$. gondii-infected trophoblastic BeWo cells [28], specialized cells of placental origin that have a central position in the control of materno-fetal passage of pathogens, including $T$. gondii [32]. Here, we wanted to study the kinetics of UHRF1 promoter activation and mRNA expressions upon $T$. gondii infection. First, host cells were transfected with an UHRF1 promoter-luciferase (UHRF1luc) reporter plasmid, followed by infection with the virulent RH strain of $T$. gondii. Infection significantly induced UHRF1 promoter activity at $3 \mathrm{~h}$ post-infection (Fig. 1a). To complete this result, UHRF1 mRNA was analyzed by quantitative reverse transcription PCR. The results also show a significant increase in UHRF1 mRNA expression at $3 \mathrm{~h}$ post-infection (Fig. 1b). UHRF1 promoter activity did also increase in non-infected cells with culture time, but slower and not to the same extent as in infected cells (Suppl. Fig. 1).

We also examined the effect of $T$. gondii infection on $U H R F 1$ promoter activity and cell cycle inhibition in astrocytes, primary targets of $T$. gondii in the brain [33]. We also observed an increase of UHRF1 promoter activity, but more gradual between 0 and $12 \mathrm{~h}$ of infection (Suppl. Fig. 2), in contrast to the sharp early peak seen in BeWo cells, as well as a visible, but less pronounced cell cycle block.

In the early phases of $T$. gondii invasion, rhoptry proteins are released into the host cell and modulate some of its processes. Some of them present kinase activity, and are crucial in the host-pathogen interactions [10,34]. To investigate the role of these secreted proteins, we pretreated the parasites with cytochalasin $\mathrm{D}$, which allows rhoptry protein discharge into the cell, but not host cell penetration of the parasite [35]. As shown in Fig. 1c, cytochalasin D-treated T. gondii were still able to stimulate UHRF1 promoter activity at $3 \mathrm{~h}$ of infection. These data strongly suggest that Toxoplasmamediated activation of the UHRF1 promoter does not need parasite penetration of the host cell, but may be promoted by rhoptry secretion into the target cells. We also looked for 
Fig. 1 T. gondii infection activates UHRF1 promoter activity and phosphorylates UHRF1. a BeWo cells were transfected with UHRF1-promoter-luciferase reporter plasmid for $24 \mathrm{~h}$, then infected for the indicated times with $T$. gondii (RH strain) at a ratio of 1:1 and assessed for luciferase activity (mean \pm SEM of three separate experiments performed in triplicate).

${ }^{*} P<0.05$, compared to control. b BeWo cells were infected for the indicated times. UHRF1 mRNA was quantified by reverse transcription and realtime PCR $($ mean \pm S.E.M. of three separate experiments performed in triplicate). ${ }^{*} P<0.05$, compared to control. $\mathbf{c}$ UHRF1 promoter activity in BeWo cells was assessed as above following infection with $T$. gondii pretreated or not with cytochalasin D. Mean \pm SEM of three separate experiments performed in triplicate. ${ }^{*} P<0.05$, compared to control. d Western blot analysis of UHRF1 protein expression in BeWo cells infected with T. gondii pretreated or not with cytochalasin D. Actin served as a loading control. Data are representative of at least three independent experiments

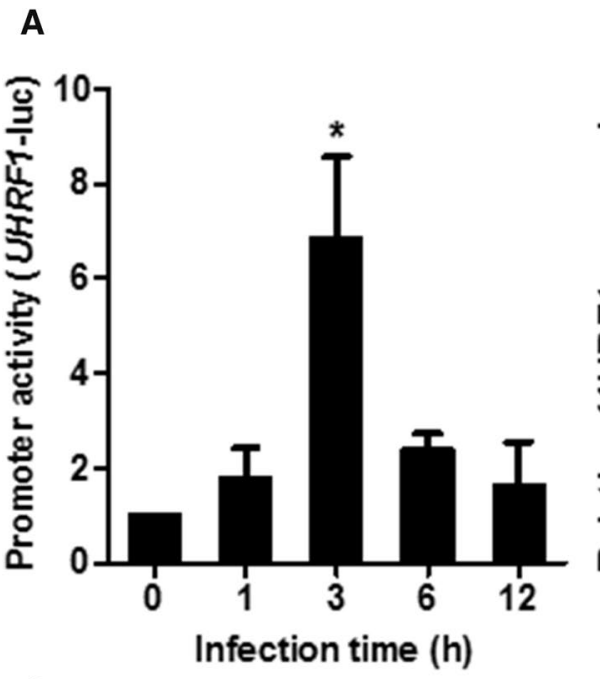

B

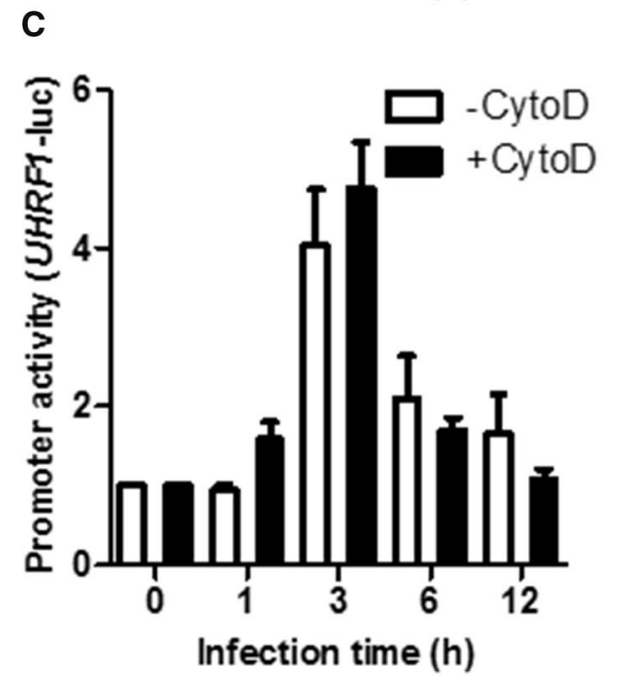

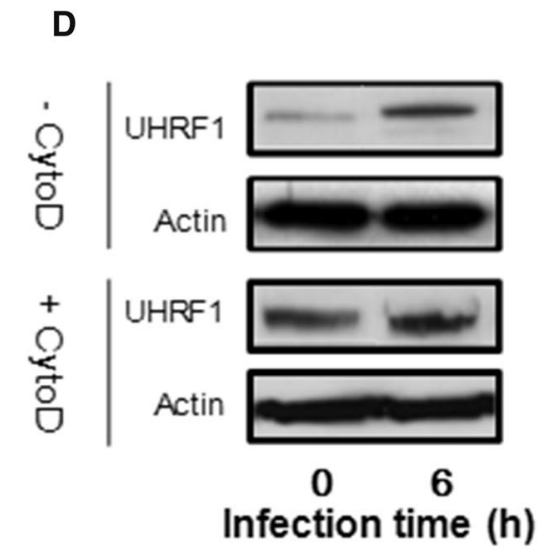

UHRF1 expression on the protein level following $T$. gondii infection, with or without cytochalasin D pre-treatment. Six hours post-infection, UHRF1 protein expression was increased in the presence or not of cytochalasin D. These results confirmed that the increase in UHRF1 expression is due to rhoptry secreted proteins and does not need parasite penetration.

\section{ROP16-dependent activation and phosphorylation of UHRF1}

To further characterize the interactions between $T$. gondii proteins and UHRF1, we employed the yeast two-hybrid technique to look for candidate proteins. The sequences of the strongest confirmed, non-redundant UHRF1-interacting clones were analyzed with bioinformatic tools, including ToxoDB (ToxoDB.org release 2.3) (data not shown). Several parasite proteins were identified, of which we selected the kinase ROP16 as the most likely candidate due to its role in parasite virulence and its demonstrated catalytic activity. We hypothesized that ROP16 might increase UHRF1 promoter activity and phosphorylate UHRF1.

To analyze if UHRF1 could be an as yet unknown substrate of the ROP16 kinase, we infected BeWo cells with an RH mutant deficient for ROP16 (RH $\Delta$ ROP16). Intracellular replication of RH $\Delta$ ROP16 parasites was similar to that of the RH WT parasites (data not shown). As shown in Fig. 2a and b, the UHRF1 promoter was not activated in cells infected with RH $\Delta$ ROP16 parasites, and UHRF1 protein expression was not increased in these cells, in contrast to cells infected with RH WT parasites.

We have previously shown that, contrary to its promoter activity, UHRF1 protein levels continuously increase up to $24 \mathrm{~h}$ post-infection [28]. Therefore, we hypothesized that T. gondii might induce post-translational modifications of the UHRF1 protein to stabilize it. Phosphorylation is an essential process in regulating the activity of nuclear proteins. Phosphorylation of UHRF1 increases its binding to the promoters of target genes [36]. Therefore, we examined 
Fig. 2 T. gondii ROP16 is responsible for UHRF1 activation and phosphorylation. a BeWo cells were transfected with UHRF1-dependent luciferase reporter plasmid for $24 \mathrm{~h}$, then infected with the RH WT or RH $\Delta$ ROP16 strains for the indicated times. Luciferase activities were analyzed and shown as mean \pm SEM of three separate experiments performed in triplicate. ${ }^{*} P<0.05$, ${ }^{* *} P<0.01$, compared to $0 \mathrm{~h}$. b Cells were infected for $6 \mathrm{~h}$ with RH WT or RH $\Delta$ ROP16 strains. Whole cell lysates were analyzed by Western blot using anti-UHRF1 antibodies. Actin served as a loading control. Data are representative of at least three independent experiments. c Immunoprecipitation of UHRF1 was performed on whole cell lysates of uninfected or $6 \mathrm{~h}$ infected cells followed by Western blot analysis of the indicated proteins. The quantitative graphs in (b) and (c) show the relative changes at $6 \mathrm{~h}$ of infection, compared to $0 \mathrm{~h}$ (mean \pm SEM of three separate experiments). ${ }^{*} P<0.05$, compared to non-infected cells

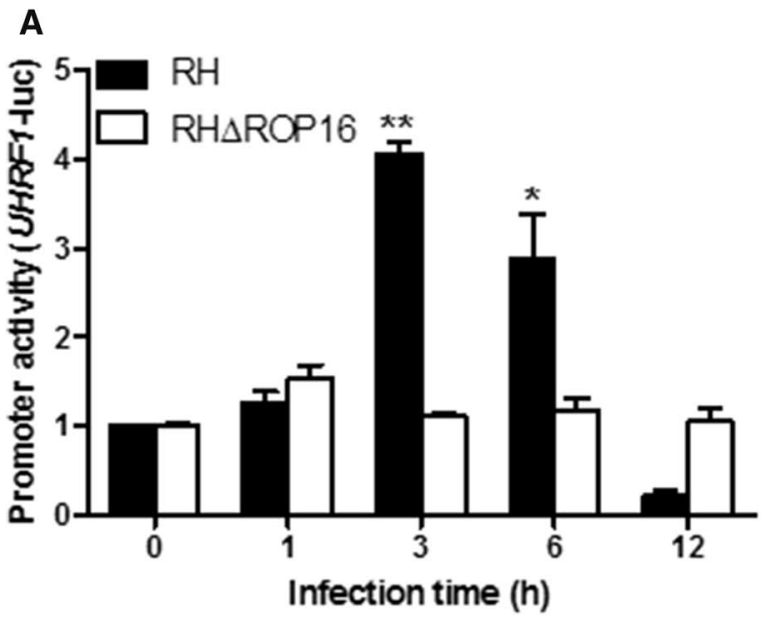

B
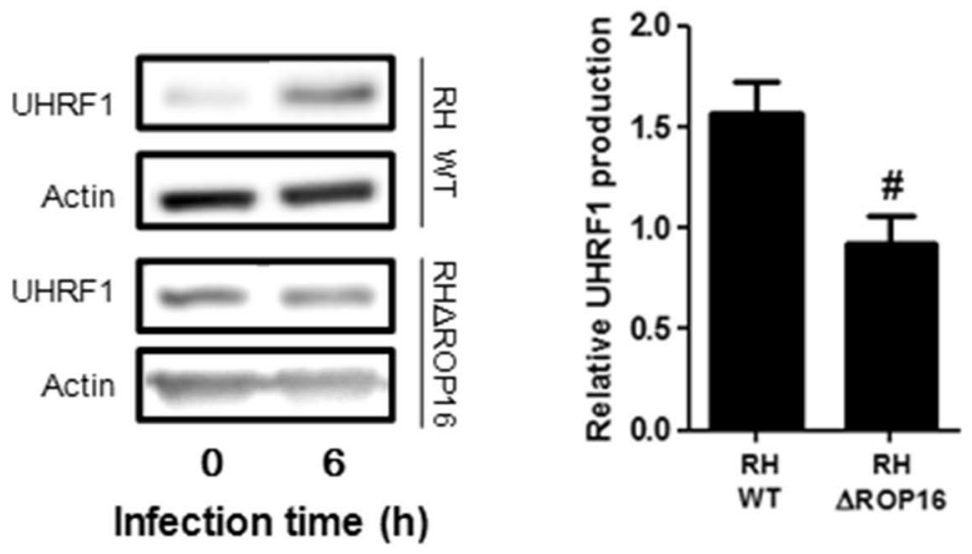

C

\section{IP UHRF1}

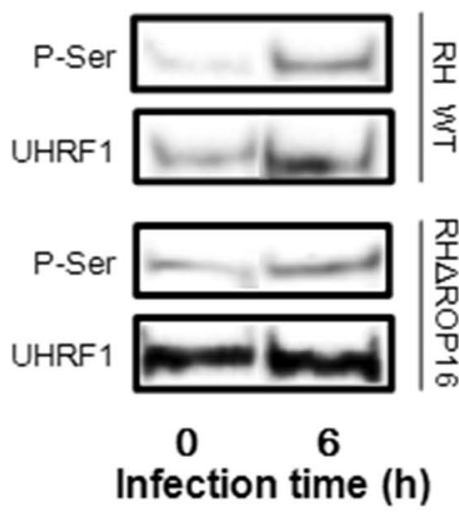

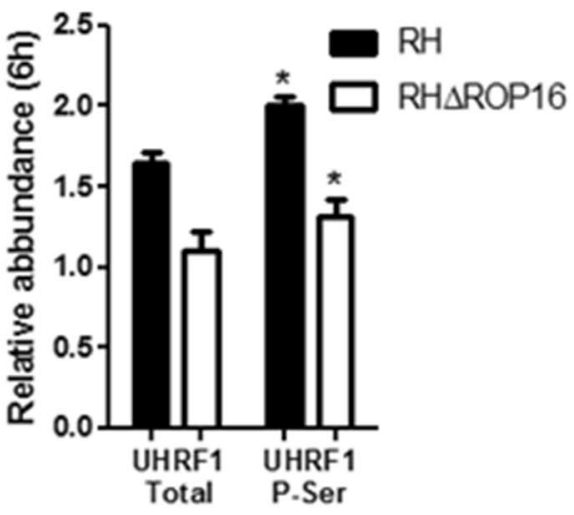

the phosphorylation of UHRF1 by immunoprecipitation of total UHRF1 protein and subsequent detection using an antibody against pan-phosphorylated serine (P-Ser). A twofold increase of phosphorylated UHRF1 was detected upon infection with RH WT, whereas this increase was less obvious with $\mathrm{RH} \Delta \mathrm{ROP} 16$ parasites (Fig. 2c). These results suggested that ROP16 is probably not the only, but a major factor for UHRF1 phosphorylation and activation.

To further investigate the influence of ROP16 and its catalytic kinase domain, a plasmid containing the gene coding for a ROP16 mutant without a functional catalytic domain (ROP16 $\Delta$ Cat) was transfected into BeWo cells. Cells were also transfected with a plasmid containing the corresponding 

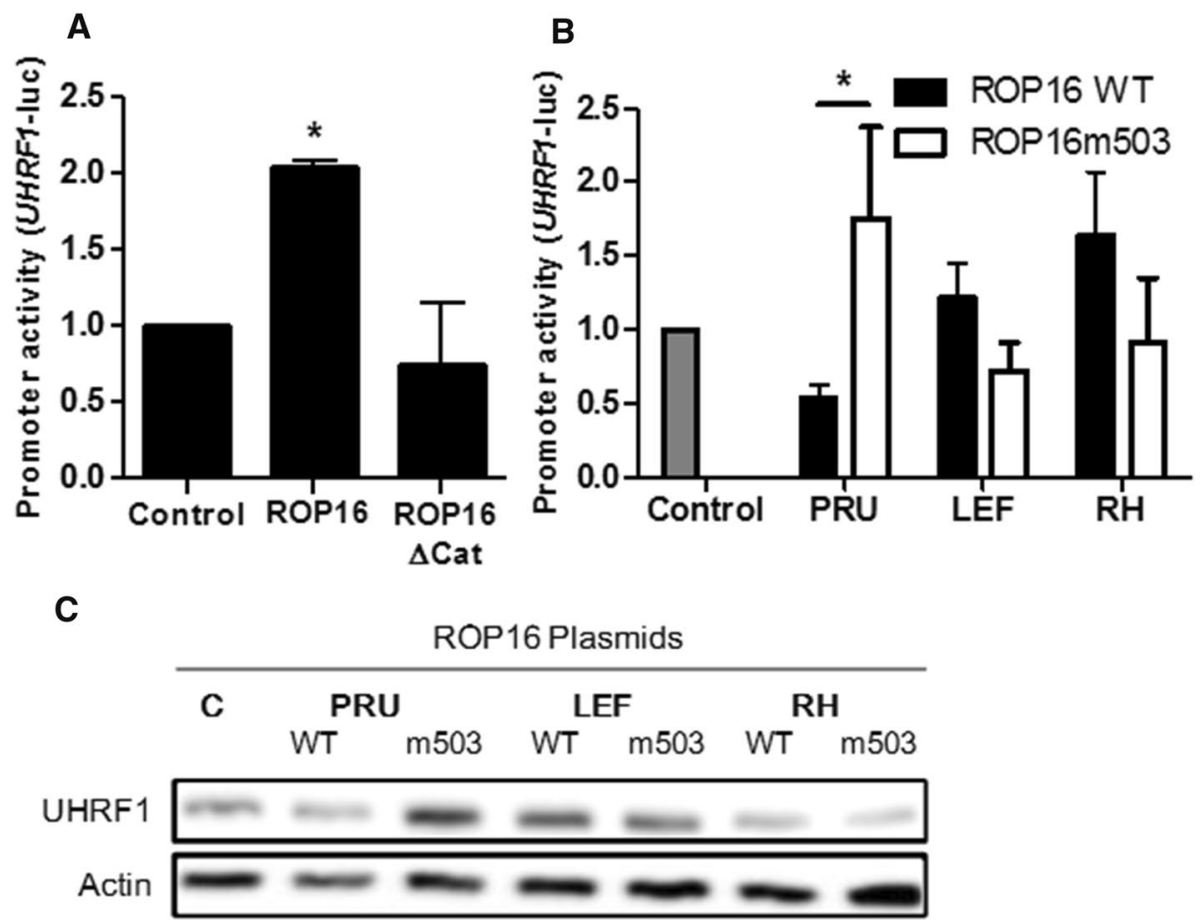

Fig. 3 A single ROP16 amino acid determines the strain-specific activation of UHRF1. a BeWo cells were transfected with UHRF1promoter-luciferase reporter plasmid for $24 \mathrm{~h}$, then with ROP16 WT, ROP16 mutant plasmid without the catalytic kinase domain (ROP16 $\Delta$ Cat) (both from $T$. gondii RH strain) or the empty control plasmid. Luciferase activity was then analyzed and shown as mean \pm SEM of three separate experiments performed in triplicate. ${ }^{*} P<0.05$, compared to control. b UHRF1 promoter activity in BeWo cells was assessed as above following transfection with

RH wild-type ROP16 and with an empty plasmid as control. As shown in Fig. 3a, overexpression of wild-type ROP16, but not ROP $16 \Delta$ Cat induced significant activation of the UHRF1 promoter.

Again, we also examined the effect of transfection of wild-type and mutant ROP16 on UHRF1 promoter activity in astrocytes We obtained similar results as in BeWo cells, with activation of UHRF1 promoter activity only upon transfection with the wild-type ROP16, but not ROP16 $\Delta$ Cat (Suppl. Fig. 3).

Together, these results demonstrate that ectopic expression of ROP16 is sufficient to activate UHRF1 promoter activity and that this activation depends on ROP16 kinase activity.

\section{A single ROP16 amino acid determines the strain-specific activation of UHRF1}

The genus Toxoplasma consists of only one species, $T$. gondii, but the parasite population is extremely diverse. For ROP16, one of the following plasmids: control plasmid (gray bar), ROP16 WT plasmids (black bars) or ROP16m503 mutant plasmids (white bars) from PRU, LEF and RH strains. Mean \pm SEM of three separate experiments performed in triplicate. ${ }^{*} P<0.05$, between ROP16 WT and ROP16m503. c Western blot analysis of UHRF1 expression in cells transfected for $24 \mathrm{~h}$ with the control plasmid, ROP16 WT or ROP16m503 mutant plasmids from PRU, LEF or RH strains. Actin served as a loading control. Data are representative of at least three independent experiments

the decisive difference between virulent and avirulent alleles for STAT3 activation has been localized to the presence of leucine or serine, respectively, at position 503 [13]. To test this hypothesis on UHRF1, different types of ROP16 mutants from different strains were produced. The ROP16 503 leucine of type I $(\mathrm{RH})$ and the atypical strain LEF were replaced by serine, and vice versa for the type II strain (PRU) ROP16, where serine was replaced by a leucine at the same position. As shown in Fig. 3b, RH and LEF 503 mutant plasmids induced less activation of the UHRF1 gene promoter than their wildtype counterparts, while the PRU 503 mutant protein activated the UHRF1 gene promoter significantly stronger than the PRU wild type.

We next analyzed UHRF1 in cells expressing the same WT or 503 ROP16 mutant proteins on the protein level and got similar results (Fig. 3c). Expression of the PRU 503 ROP16 mutant strongly increased UHRF1 protein levels. Taken together, these results suggest that this single locus on amino acid at 503 determines the impact of ROP16 on UHRF1 expression. 


\section{UHRF1 is recruited to the cyclin B1 gene promoter and suppresses its expression in Toxoplasma-infected cells}

We have previously reported that UHRF1 is exploited by T. gondii to control CCNBI gene expression. In T. gondiiinfected cells, increased levels of UHRF1 inversely correlate with levels of cyclin B1, leading to cell cycle dysregulation. mRNA levels of UHRF1 and cyclin B1 paralleled protein levels, meaning that these variations reflect changes in gene transcription [28]. To further establish whether UHRF1 is necessary and sufficient for $C C N B 1$ silencing, we transfected BeWo cells with UHRF1-siRNA plasmids in the presence or absence of T. gondii and evaluated cyclin B1 expression (Fig. 4a). Cells transfected with an EGFP-siRNA expression plasmid were used as controls. We observed a reversal of the infection-induced cyclin B1 kinetics in UHRF1 knockdown cells. A significant increase in cyclin B1 levels was observed at $12 \mathrm{~h}$ of infection in UHRF1 knock-down cells, compared with cells transfected with EGFP-siRNA, whereas lower expression is seen for earlier time points. These results indicate that UHRF1 is involved in cyclin B1 deregulation in T. gondii-infected cells.

To establish if UHRF1 is directly involved in cyclin B1 downregulation, we examined the recruitment of UHRF1 to the $C C N B 1$ promoter during infection, by chromatin immunoprecipitation (ChIP) assay (Fig. 4b). We observed enhanced UHRF1 binding to the $C C N B 1$ promoter at $3 \mathrm{~h}$ of infection. Control PCRs using primers for GAPDH cDNA demonstrated the specificity of UHRF1 precipitation (Suppl. Fig. 4). Together, these results show that, during T. gondii infection, UHRF1 negatively regulates cyclin $\mathrm{B} 1$ expression through recruitment on the $C C N B 1$ promoter.

\section{UHRF1 interacts with a multienzymatic complex on the cyclin B1 promoter to induce histone modifications}

Following our previous finding that $T$. gondii downregulates cyclin B1 expression through UHRF1 activation and considering the established role of UHRF1 in epigenetic modification, we hypothesized that it might regulate cyclin B1 expression by interfering with the epigenetic machinery. UHRF1 is part of a multienzymatic chromatin-modifying complex [37]. To further characterize these UHRF1 containing immune complexes in $T$. gondii-infected cells, we immunoprecipitated UHRF1 at different time points and identified binding partners by mass spectrometrybased proteomics. SDS-PAGE gel of cell lysates, stained by Coomassie blue is presented in supplementary data (Suppl. Fig. 5). Altogether, 474, 564, 1063, 512 and 399 proteins were identified at $t=0 \mathrm{~h}, t=1 \mathrm{~h}, t=3 \mathrm{~h}, t=6 \mathrm{~h}$ and $t=12 \mathrm{~h}$, respectively (Suppl. Fig. 6). Seven proteins
A
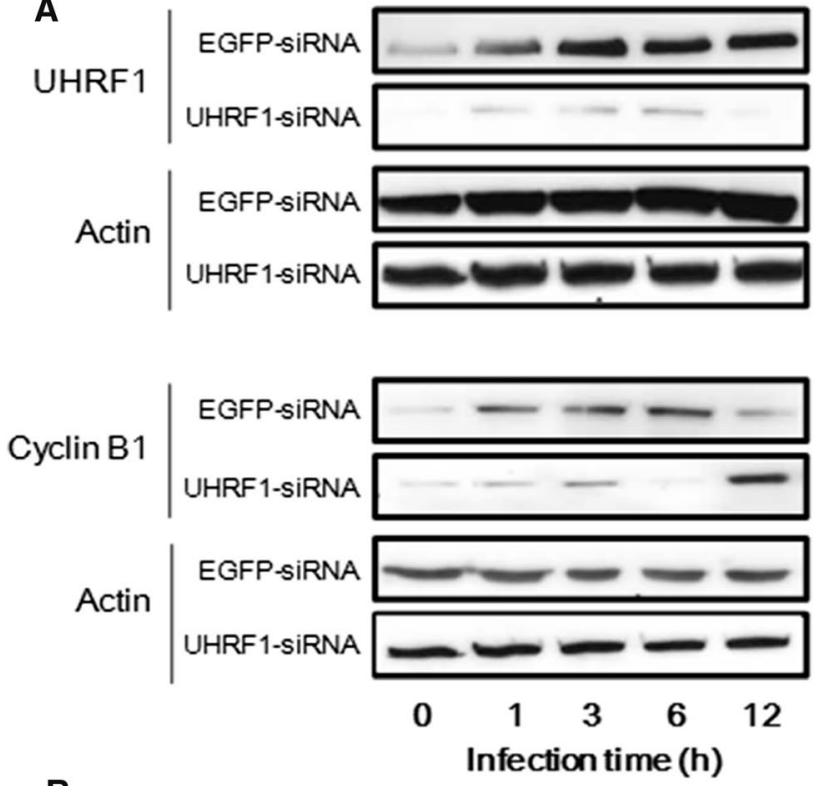

B

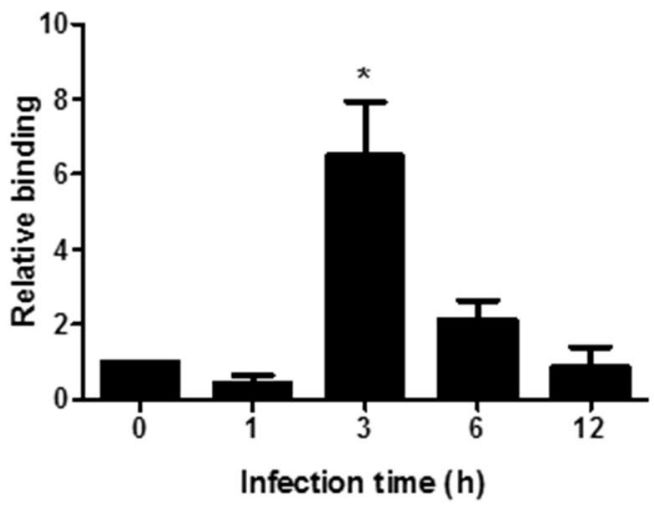

Fig. 4 UHRF1 regulates cyclin B1 expression in T. gondii-infected cells. a BeWo cells were transfected with UHRF1-siRNA or EGFPsiRNA plasmid vectors and infected for the indicated times with $T$. gondii at a ratio of 1:1. UHRF1, cyclin B1 and actin proteins were then analyzed by Western blot. Data are representative of at least three independent experiments. b Binding of UHRF1 to CCNB1 promoter in infected cells. BeWo cells were infected with $T$. gondii for the indicated times at a moi of 4:1. ChIP assay was performed using antibodies against UHRF1, or actin as negative control. Immunocomplexes were then analyzed by real-time PCR specific for the promoter region of $C C N B 1$. Non-immunoprecipitated chromatin material was used as input control. The results were normalized to the input DNA and expressed as relative binding, compared to non-infected cells. Data are mean \pm SEM of three separate experiments. ${ }^{*} P<0.05$, compared to non-infected cells

implicated in cell cycle control were identified at different time points (Fig. 5). All binding UHRF1 partners were validated by immunoprecipitation (data not shown). As shown in Fig. 5, we observed time-dependent interactions with the epigenetic-related proteins HDAC1 and HDAC2, PCNA, DNMT1, USP7, and HP1ß. 


\begin{tabular}{|c|c|c|c|c|c|}
\hline Infection time (h) & 0 & 1 & 3 & 6 & 12 \\
\hline $\begin{array}{c}\text { Recruited } \\
\text { HAT1 }\end{array}$ & HDAC1 & HDAC1 & \\
\hline $\begin{array}{c}\text { Histone-modifying } \\
\text { Enzymes }\end{array}$ & PCNA & PCNA & PCNA & PCNA & PCNA \\
\hline
\end{tabular}

Fig. 5 UHRF1 recruits a multienzymatic complex in $T$. gondiiinfected cells. BeWo cells were infected with $T$. gondii for the indicated times at a ratio of 1:1. Whole protein cell lysates were separated by SDS-PAGE. Gel slices were cut in a systematic way and proteins were reduced, alkylated, and digested. The resulting peptides were

We hypothesized that these interactions with histone deacetylases and methyltransferases might affect the histone marks on the CCNB1 promoter in the course of infection. To clarify these time-dependent changes, ChIP assays were performed using antibodies against acetyl-H3 and H3K9me3, followed by $C C N B 1$-specific PCR. We found a decrease of acetyl-H3 on the $C C N B 1$ promoter at $6 \mathrm{~h}$ post-infection (Fig. 6a), paralleled by an increase of $\mathrm{H} 3 \mathrm{~K} 9$ trimethylation (Fig. 6b). These results indicate that HDAC and methyltransferases, recruited with UHRF1 to the $C C N B 1$ promoter after infection, induce specific changes in histone acetylation and methylation levels.

\section{T. gondii activates DNMT expression in infected cells and regulates gene expression via DNA methylation}

To get insight into the potential mechanisms of altered methylation status in infected cells, we determined the expression

\section{A}

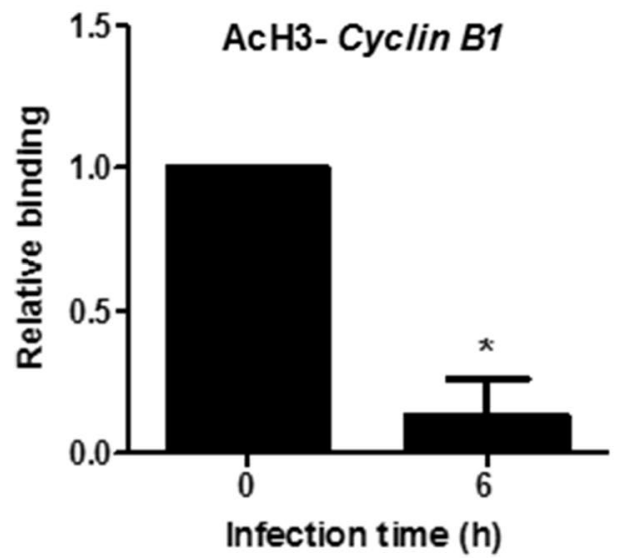

Fig. 6 T. gondii interferes with histone $\mathrm{H} 3$ acetylation and methylation on cyclin B1 promoter. BeWo cells were infected for the indicated times with $T$. gondii at a moi of 1:1. ChIP assay was performed using antibodies against acetyl-histone $3 \mathbf{a}$ and trimethyl-H3 (Lys9) b or an isotype control antibody. The precipitated DNA was then ampli- analyzed by nanoLC-MS/MS. Proteins were identified through database searching, using a mixed human and toxo decoy database with a $1 \%$ false discovery rate. MS/MS spectra of the seven proteins of interest were extracted and manually validated to confirm the identifications

levels of the different DNMTs in T. gondii-infected cells. DNMT1 maintains the methylation pattern during replication, while DNMT3a and DNMT3b are de novo methyltransferases [38]. Our previous results led us to hypothesize that $T$. gondii could modulate DNMT activity to epigenetically silence the expression of target genes. We examined global DNMT activity in infected cells (Fig. 7a). Indeed, a significantly increased DNMT activity was evident as early as $3 \mathrm{~h}$ of infection. Quantitative RT-PCR analysis revealed that expression levels of DNMT1 were increased by parasite infection (Fig. 7b). In addition, to examine the $T$. gondii infection global methylation status, we performed a methylation-sensitive PCR of LINE sequences which are dispersed throughout the genome. As shown in Fig. 7c, methylated LINE sequences increased with infection, while unmethylated sequences decreased at the same time. Together, these results support our hypothesis that $T$. gondii infection induces hypermethylation of host genome DNA by

\section{B}

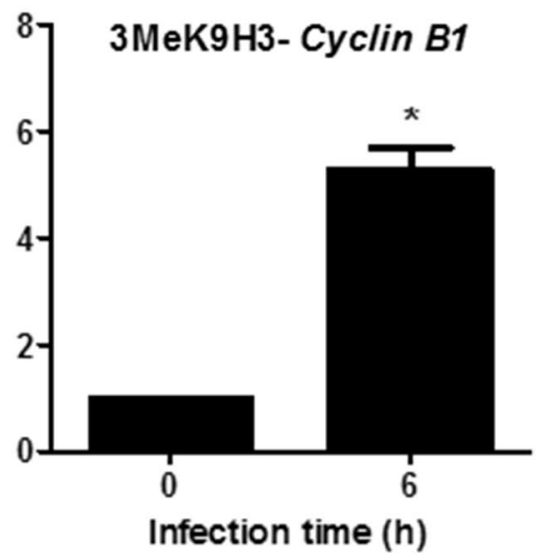

fied by real-time PCR for $C C N B 1$ promoter region. The results were normalized to the input DNA and expressed as relative binding, compared to non-infected cells. Data are mean \pm SEM of three separate experiments. ${ }^{*} P<0.05$, compared to non-infected cells 
Fig. 7 T. gondii induces DNMT expression and methylation activity. a The global DNMT activity during infection was analyzed by an ELISA-based method, as detailed in the methods section. b Cells were infected for the indicated times with $T$. gondii at a ratio of 1:1. DNMT1 mRNA levels were quantified by RT-PCR and presented relative to GAPDH expression. c BeWo cells were infected with $T$. gondii at. DNA was extracted and subjected to bisulfite treatment. Methylation of the LINE1 sequence was assessed by PCR specific for methylated (M) or unmethylated (UM) sequences. Data are mean \pm SEM of three separate experiments. ${ }^{*} P<0.05$, compared to non-infected cells
A

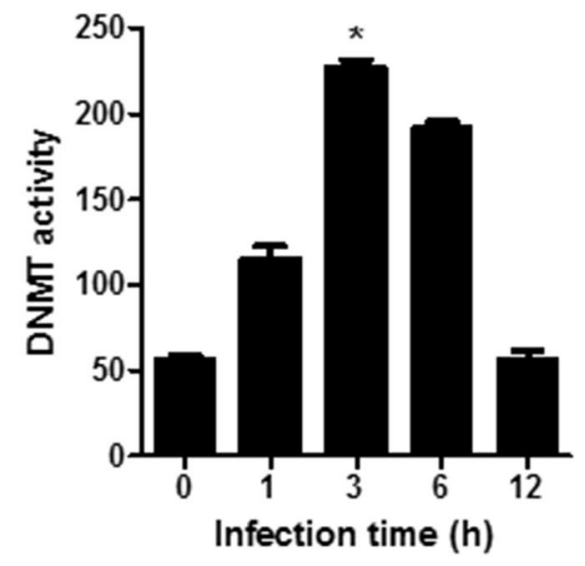

C

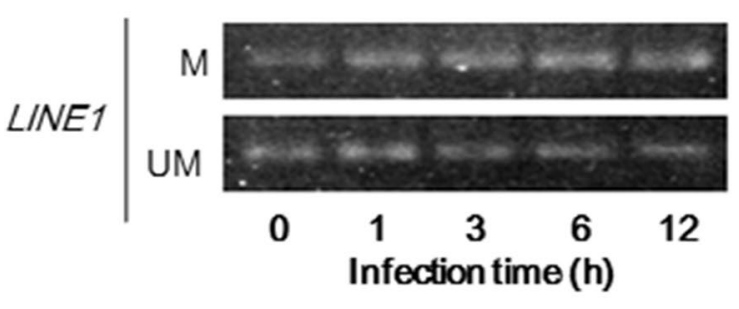

B
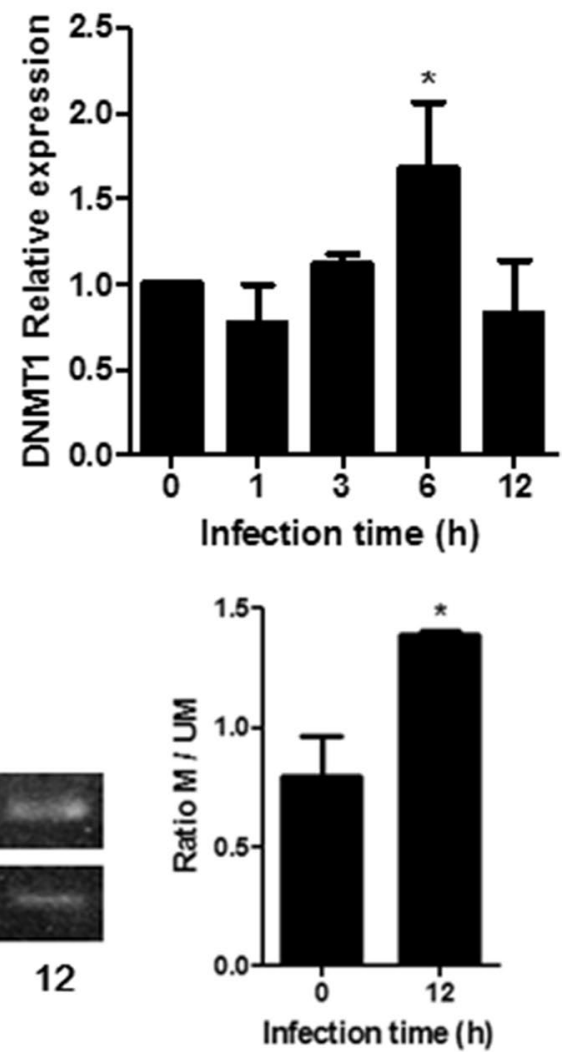

increasing mediation by DNMT1 mRNA, protein levels and the global DNMT activity.

\section{T. gondii ROP16 kinase affects cyclin B1 expression and host cell cycle modulation}

Our previous results show an UHRF1-mediated regulation of $T$. gondii-infected cell cycle. To analyze the role of ROP16 in this process, we infected cells with RH WT and RH $\Delta$ ROP16 strains, and analyzed cyclin B1 expression levels and cell cycle (Fig. 8a, b). Infection with RH $\Delta$ ROP16 parasites did not result in decreased cyclin B1 expression, in contrast to the RH WT strain. Moreover, no augmentation of cells in G2/M phase was observed when infected with RH $\Delta$ ROP16 Toxoplasma strain, again in contrast to the RH WT strain. Percentages of cells in the different cell cycle phases during RH $\Delta$ ROP16 infection are shown in Suppl. Figure 7. Together, these results indicate that cyclin B1 and UHRF1-dependant cell cycle regulation in infected cells are ROP16 dependent.

\section{Discussion}

The cell cycle is a target for intracellular microorganisms. For example, in HIV infection, cell cycle dysregulation is associated with enhanced virus proliferation [39]. We and others demonstrated such mechanisms with $T$. gondii infection, which induces an inhibition of cellular proliferation through arrest of the host cell cycle in the G2 phase via UHRF1 activation [28, 40]. The benefit of this modulation for the parasite remains unknown. Previous studies indicated an optimized nutrient acquisition or a compromised mitosis by parasite-induced rearrangement of host cell microtubules and recruitment of the microtubule organizing center to the parasitophorous vacuole membrane [41]. We previously showed that the cell cycle arrest is linked to a downregulation of $C C N B 1$ gene expression, associated with an overexpression of UHRF1 [28]. However, the parasitic factors inducing UHRF1 activation as well as the mechanisms of cell cycle regulation were unknown. Some authors hypothesized interactions between parasite proteins that cross the parasitophorous vacuole membrane and cyclin/CDK complexes that may affect their catalytic activities [40]. Recently, overexpression of the parasite kinase ROP16 was shown to be involved in Ser15/37 phosphorylation of p53, partial apoptosis of SH-SY5Y cells and cell cycle arrest in G1 stage [37]. We show here that ROP16 is one of the factors responsible for the UHRF1 activation, which in turn causes the down-regulation of cyclin B1 and the G2 cell cycle arrest. We demonstrate that activated UHRF1 is recruited to the $C C N B 1$ promoter during infection and induces epigenetic modifications, resulting in the formation 
Fig. 8 ROP16 plays a central role in UHRF1-dependant cyclin $\mathrm{B} 1$ regulation. a BeWo cells were infected for the indicated times with $T$. gondii RH WT or RH $\Delta$ ROP16 strains at a ratio of 1:1. Samples were analyzed by Western blot using antibodies against cyclin B1 or actin as loading control. Bands of three blots were analyzed by densitometry. b BeWo infected with $T$. gondii RH WT or $\mathrm{RH} \Delta \mathrm{ROP} 16$ strains were analyzed for cell cycle progression by flow cytometry of propidium iodide. Data are mean \pm SEM of three separate experiments ${ }^{*} P<0.05$, compared to noninfected cells
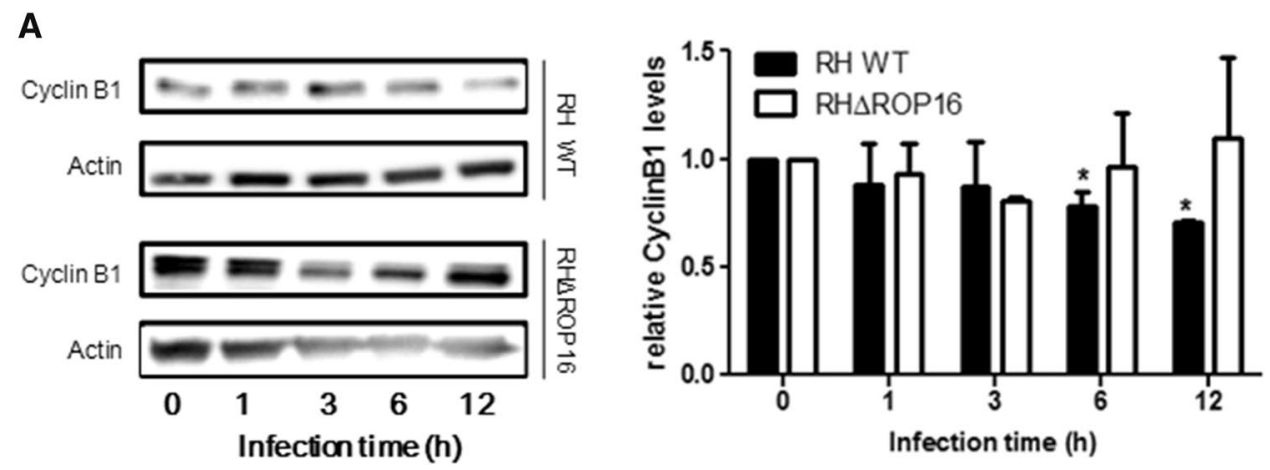

B

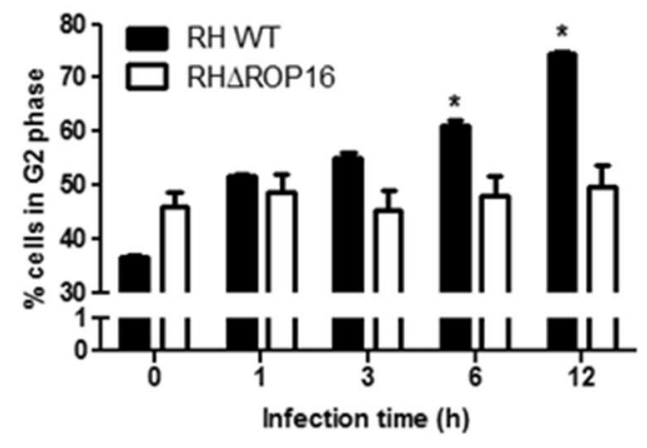

of a heterochromatin environment and repression of the CCNB1 promoter activity. This is the first report demonstrating that a parasitic infection, via its kinase ROP16, activates a transcription factor, UHRF1, leading to an epigenetic regulation process.

UHRF1 is a multi-domain-containing protein involved in epigenetic regulation through DNA methylation, histone deacetylation and methylation, and likely histone ubiquitination [23, 24]. To determine with which partners UHRF1 interacts with after $T$. gondii infection, we analyzed the enzymatic complexes associated with UHRF1 by mass spectrometry. Our results in infected cells show that UHRF1 interacts with HDAC1 and 2, and DNMT1 to form a repressive complex. Recruitment of this enzymatic complex leads to deacetylation of histone $\mathrm{H} 3$ and methylation of histone $\mathrm{H} 3 \mathrm{~K} 9$ on the $C C N B 1$ promoter, and consequently to its silencing. Besides histone modification, we also show that $T$. gondii infection causes DNA hypermethylation in the host cell by upregulation of DNMTs. H3K9 methylation and DNA methylation are well known to contribute to gene repression [37]. While this mechanism has never been described in a parasite infection model, in sporadic breast cancer, UHRF1 was shown to induce DNA methylation, as well as histone deacetylation and methylation on the $B R C A 1$ promoter by recruitment of an inhibitory transcriptional complex similar to the one we observed here [42]. The SRA domain of UHRF1 directly interacts with 5-hydroxymethylcytosine and hemi-methylated DNA and PCNA, which helps to recruit DNMT1 and stimulate its enzymatic activity [22, 43]. The
TTD/PHD domains interact with methylated H3K9 which stimulates the enzymatic activity of H3K9 methyltransferases (H3K9MT) and thus methylation of adjacent H3K9, resulting in heterochromatin formation and gene silencing $[24,44]$.

During our mass spectrometry-based proteomics, we also show that UHRF1 interacts with USP7 in infected cells. USP7 (HAUSP) is a deubiquitylase that regulates DNMT1 and UHRF1 stability [45]. It is also targeted by $T$. gondii GRA16, binding PP2A-B55 to modulate genes involved in metabolism, cell cycle progression, and p53 tumor suppressor pathway [15]. Indeed, USP7 mediates deubiquitylation of UHRF1, preventing its proteasomal degradation. Moreover, UHRF1 is released from USP7 at the M phase of the cell cycle after its phosphorylation by CDK1-cyclin B1, leading to UHRF1 degradation [46]. Together with our results, this underlines once more the importance of cell cycle dysregulation in infected cells for maintaining a sufficient level of UHRF1 activity for parasite proliferation.

Precise molecular mechanisms of UHRF1 domain interaction with the $C C N B 1$ promoter in parasite-dependent epigenetic events still need to be explored. However, based on our data, a global modeling of this interaction can be proposed (Fig. 9a). T. gondii modulates CCNBI gene expression by interfering with methylation and histone modifications. The recruitment of UHRF1 to the CCNB1 promoter induces deacetylation of histone $\mathrm{H} 3$, by recruitment of HDAC 1 and 2. UHRF1 also recruits histone lysine methyltransferases which methylate the histone H3 

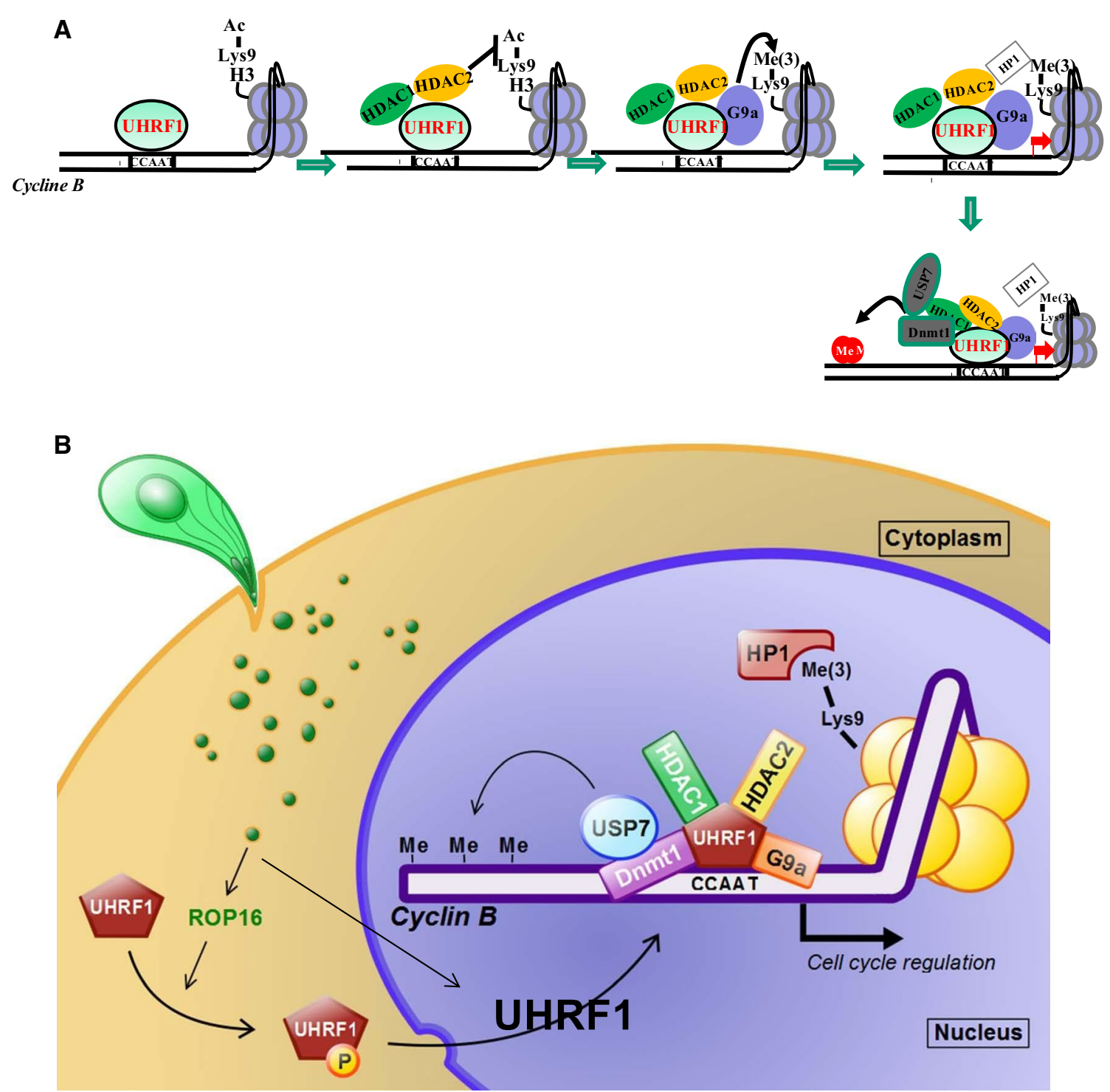

Fig. 9 Model of UHRF1-mediated cyclin B1 repression in T. gondiiinfected cells. a In infected cells, the transcription factor UHRF1 binds to the CCNB1 promoter where it recruits the histone deacetylases HDAC1 and 2 to promote local deacetylation of histone H3. UHRF1 also recruits histone methyltransferases which induce dimethylation of histone $\mathrm{H} 3$ allowing the recruitment of heterochromatin protein 1 (HP1 $\beta)$. Finally, the DNA methyltransferase DNMT1 is recruited inducing DNA methylation on the $C C N B 1$ promoter and thus heterochromatin formation and $C C N B 1$ gene silencing. b Model of Toxoplasma-induced regulation of cyclin B1 expression and allow HP1 $\beta$ binding and heterochromatin formation. Finally, DNMTs are recruited by UHRF1 to methylate and silence the $C C N B 1$ promoter, resulting in cell cycle arrest in $\mathrm{G} 2$ phase. There is a similar example of the co-repressor COUP-TF interacting protein 2 (CTIP2) inhibiting HIV-1 gene transcription by recruiting a chromatin-modifying complex and by establishing a heterochromatic environment at the HIV- 1 promoter in microglial cells, leading to HIV-1 silencing [47].

ROP16 is a polymorphic $T$. gondii protein kinase, targeting the host cell nucleus and known to directly induce phosphorylation of STAT3 and STAT6 $[9,13]$. We show here that ROP16 also targets UHRF1. Our results suggest that UHRF1 is phosphorylated by ROP16 as an early event in cell invasion. Yamamoto et al. demonstrated that substitution of a single amino acid at position 503 (at the serine-threonine kinase domain) of the ROP16 protein in $\mathrm{RH}$ and Me49 strains determined a change in their activation of STAT3 [34]. Confirming the before mentioned findings for STAT3, we show that only the virulent isotype of ROP16 activates the UHRF1 gene promoter. This could be one clue to explain the mechanisms behind the striking differences on 
cytokine induction and parasite control between ROP16 isotypes in our recent in vivo study [11]. Preliminary work on PRU (type II) parasites, which contain the avirulent ROP16 isotype showed a graduate, but much less pronounced upregulation of UHRF1, while the cell cycle shows a considerably delayed (12-24 h) and less pronounced block, compared to type I infection (our own observation). This indicates that other factors besides ROP16 might interfere with host cell cycle, but they are likely to use other pathways and are obviously less effective. The in silico profile of the ROP16 protein of different strains should be explored, as Yamamoto et al. [13] had found that the residue at position 503 (leucine) in the RH strain is completely inaccessible to the substrate and that the cavity was larger for type II Me49 strain making the site more active.

Our results lead us to hypothesize that ROP16 injected early in infected cells phosphorylates UHRF1. In turn, phosphorylated UHRF1 translocates to the host nucleus and recruits the epigenetic complex leading to $C C N B 1$ promoter silencing and the observed cell cycle arrest in $\mathrm{G} 2 / \mathrm{M}$ (Fig. 9b). As indicated by the lesser, but still visible increase of phosphorylated UHRF1 during RH $\Delta$ ROP16 infection, other p53-related mechanisms may be involved in the fine tuning of the cell cycle. Regulation in early stages of invasion through ROP16 or later through the secretion of proteins such as GRA16, GRA24 or MYR1 could maintain the non-replicative status of the cell $[15,29,48]$.

Pathogen-induced alterations of host cell physiology aim to maximize its survival. Histone modifications and chromatin remodeling regulating gene expression should be key targets for intracellular parasites. In bacteria- or virusinduced host gene reprogramming, targets are the MAPK, IFN and NF- $\kappa B$ signaling pathways [49]. Well known in cancer development [24, 42], but unknown in host-pathogen interactions, we show the role played by UHRF1 during Toxoplasma parasitic infection.

In summary, we demonstrate in our model of trophoblastic cells that $T$. gondii ROP16 kinase activates UHRF1, which in turn regulates $C C N B 1$ epigenetic silencing through its recruitment on the $C C N B 1$ promoter and correlates with cell cycle dysregulation in these cells. Our data suggest that $C C N B 1$ epigenetic silencing is coordinated by UHRF1 through both DNA and histone methylation. Adding to the known transcription factors activated during infection, NF- $\kappa$ B, c-Fos, EGR1, c-Myc, STAT3/6, HIF1- $\alpha$ or NFAT4A, we can now include UHRF1, which emerges as an important epigenetic initiator regulating gene expression in $T$. gondii-infected cells along with NF- $\mathrm{BB}, \mathrm{p} 53$, c-Myc STAT and HIF1- $\alpha$ [17]. Most likely, CCNB1 is not the only gene targeted by UHRF1 and regulated in an epigenetic manner in infected cells, and further studies should broaden our understanding on this central transcription factor for $T$. gondii infection.
Acknowledgements The Toxoplasma research of the laboratory is supported by the Centre National de Référence Toxoplasma. The authors would like to thank Motoko Unoki for the UHRF1 tools, Mohamed-Ali Hakimi for the Toxoplasma RH $\Delta$ ROP16 strain, Valentin LeDouce for help with Fig. 9 and Lydia Arnoux for valuable technical assistance.

Open Access This article is distributed under the terms of the Creative Commons Attribution 4.0 International License (http://creativeco mmons.org/licenses/by/4.0/), which permits unrestricted use, distribution, and reproduction in any medium, provided you give appropriate credit to the original author(s) and the source, provide a link to the Creative Commons license, and indicate if changes were made.

\section{References}

1. Montoya JG, Liesenfeld O (2004) Toxoplasmosis. Lancet 363(9425):1965-1976. https://doi.org/10.1016/s0140 $-6736(04) 16412-\mathrm{x}$

2. Sibley LD, Boothroyd JC (1992) Virulent strains of Toxoplasma gondii comprise a single clonal lineage. Nature 359(6390):82-85. https://doi.org/10.1038/359082a0

3. Su C, Khan A, Zhou P, Majumdar D, Ajzenberg D, Darde ML, Zhu XQ, Ajioka JW, Rosenthal BM, Dubey JP, Sibley LD (2012) Globally diverse Toxoplasma gondii isolates comprise six major clades originating from a small number of distinct ancestral lineages. Proc Natl Acad Sci USA 109(15):5844-5849. https://doi. org/10.1073/pnas.1203190109

4. Hakimi MA, Bougdour A (2015) Toxoplasma's ways of manipulating the host transcriptome via secreted effectors. Curr Opin Microbiol 26:24-31. https://doi.org/10.1016/j.mib.2015.04.003

5. Denkers EY, Schneider AG, Cohen SB, Butcher BA (2012) Phagocyte responses to protozoan infection and how Toxoplasma gondii meets the challenge. PLoS Pathog 8(8):e1002794. https:// doi.org/10.1371/journal.ppat.1002794

6. Graumann K, Hippe D, Gross U, Luder CG (2009) Mammalian apoptotic signalling pathways: multiple targets of protozoan parasites to activate or deactivate host cell death. Microbes Infect 11(13):1079-1087. https://doi.org/10.1016/j.micinf.2009.08.011

7. Jensen KD, Hu K, Whitmarsh RJ, Hassan MA, Julien L, Lu D, Chen L, Hunter CA, Saeij JP (2013) Toxoplasma gondii rhoptry 16 kinase promotes host resistance to oral infection and intestinal inflammation only in the context of the dense granule protein GRA15. Infect Immun 81(6):2156-2167. https://doi.org/10.1128/ IAI.01185-12

8. Melo MB, Jensen KD, Saeij JP (2011) Toxoplasma gondii effectors are master regulators of the inflammatory response. Trends Parasitol. https://doi.org/10.1016/j.pt.2011.08.001

9. Ong YC, Reese ML, Boothroyd JC (2010) Toxoplasma rhoptry protein 16 (ROP16) subverts host function by direct tyrosine phosphorylation of STAT6. J Biol Chem 285(37):28731-28740. https ://doi.org/10.1074/jbc.M110.112359

10. Saeij JP, Coller S, Boyle JP, Jerome ME, White MW, Boothroyd JC (2007) Toxoplasma co-opts host gene expression by injection of a polymorphic kinase homologue. Nature 445(7125):324-327. https://doi.org/10.1038/nature05395

11. Rochet E, Argy N, Greigert V, Brunet J, Sabou M, Marcellin L, dela-Torre A, Sauer A, Candolfi E, Pfaff AW (2019) Type I ROP16 regulates retinal inflammatory responses during ocular toxoplasmosis. PLoS One 14(3):e0214310. https://doi.org/10.1371/journ al.pone.0214310

12. Rosowski EE, Lu D, Julien L, Rodda L, Gaiser RA, Jensen KD, Saeij JP (2011) Strain-specific activation of the NF-kappaB 
pathway by GRA15, a novel Toxoplasma gondii dense granule protein. J Exp Med 208(1):195-212. https://doi.org/10.1084/ jem.20100717

13. Yamamoto M, Standley DM, Takashima S, Saiga H, Okuyama M, Kayama H, Kubo E, Ito H, Takaura M, Matsuda T, Soldati-Favre D, Takeda K (2009) A single polymorphic amino acid on Toxoplasma gondii kinase ROP16 determines the direct and strainspecific activation of Stat3. J Exp Med 206(12):2747-2760. https ://doi.org/10.1084/jem.20091703

14. Gay G, Braun L, Brenier-Pinchart MP, Vollaire J, Josserand V, Bertini RL, Varesano A, Touquet B, De Bock PJ, Coute Y, Tardieux I, Bougdour A, Hakimi MA (2016) Toxoplasma gondii TgIST co-opts host chromatin repressors dampening STAT1dependent gene regulation and IFN-gamma-mediated host defenses. J Exp Med 213(9):1779-1798. https://doi.org/10.1084/ jem.20160340

15. Bougdour A, Durandau E, Brenier-Pinchart MP, Ortet $\mathrm{P}$, Barakat M, Kieffer S, Curt-Varesano A, Curt-Bertini RL, Bastien O, Coute Y, Pelloux H, Hakimi MA (2013) Host cell subversion by Toxoplasma GRA16, an exported dense granule protein that targets the host cell nucleus and alters gene expression. Cell Host Microbe 13(4):489-500. https://doi.org/10.1016/j.chom.2013.03.002

16. Bougdour A, Tardieux I, Hakimi MA (2014) Toxoplasma exports dense granule proteins beyond the vacuole to the host cell nucleus and rewires the host genome expression. Cell Microbiol 16(3):334-343. https://doi.org/10.1111/cmi.12255

17. Cheeseman K, Weitzman JB (2015) Host-parasite interactions: an intimate epigenetic relationship. Cell Microbiol 17(8):1121-1132. https://doi.org/10.1111/cmi.12471

18. Leng J, Denkers EY (2009) Toxoplasma gondii inhibits covalent modification of histone $\mathrm{H} 3$ at the IL-10 promoter in infected macrophages. PLoS One 4(10):e7589. https://doi.org/10.1371/journ al.pone.0007589

19. Rosowski EE, Nguyen QP, Camejo A, Spooner E, Saeij JP (2014) Toxoplasma gondii Inhibits gamma interferon (IFN-gamma)- and IFN-beta-induced host cell STAT1 transcriptional activity by increasing the association of STAT1 with DNA. Infect Immun 82(2):706-719. https://doi.org/10.1128/IAI.01291-13

20. Lang C, Hildebrandt A, Brand F, Opitz L, Dihazi H, Luder CG (2012) Impaired chromatin remodelling at STAT1-regulated promoters leads to global unresponsiveness of toxoplasma gondii-infected macrophages to IFN-gamma. PLoS Pathog 8(1):e1002483. https://doi.org/10.1371/journal.ppat.1002483

21. Abdulai-Saiku S, Vyas A (2017) Loss of predator aversion in female rats after Toxoplasma gondii infection is not dependent on ovarian steroids. Brain Behav Immun 65:95-98. https://doi. org/10.1016/j.bbi.2017.04.005

22. Arita K, Ariyoshi M, Tochio H, Nakamura Y, Shirakawa M (2008) Recognition of hemi-methylated DNA by the SRA protein UHRF1 by a base-flipping mechanism. Nature 455(7214):818-821. https ://doi.org/10.1038/nature07249

23. Bostick M, Kim JK, Esteve PO, Clark A, Pradhan S, Jacobsen SE (2007) UHRF1 plays a role in maintaining DNA methylation in mammalian cells. Science 317(5845):1760-1764. https://doi. org/10.1126/science.1147939

24. Bronner C, Krifa M, Mousli M (2013) Increasing role of UHRF1 in the reading and inheritance of the epigenetic code as well as in tumorogenesis. Biochem Pharmacol 86(12):1643-1649. https:// doi.org/10.1016/j.bcp.2013.10.002

25. Unoki M, Nishidate T, Nakamura Y (2004) ICBP90, an E2F-1 target, recruits HDAC1 and binds to methyl-CpG through its SRA domain. Oncogene 23(46):7601-7610. https://doi.org/10.1038/ sj.onc. 1208053

26. Sharif J, Muto M, Takebayashi S, Suetake I, Iwamatsu A, Endo TA, Shinga J, Mizutani-Koseki Y, Toyoda T, Okamura K, Tajima S, Mitsuya K, Okano M, Koseki H (2007) The SRA protein Np95 mediates epigenetic inheritance by recruiting Dnmt 1 to methylated DNA. Nature 450(7171):908-912. https://doi.org/10.1038/ nature06397

27. Unoki M, Brunet J, Mousli M (2009) Drug discovery targeting epigenetic codes: the great potential of UHRF1, which links DNA methylation and histone modifications, as a drug target in cancers and toxoplasmosis. Biochem Pharmacol 78(10):1279-1288. https ://doi.org/10.1016/j.bcp.2009.05.035

28. Brunet J, Pfaff AW, Abidi A, Unoki M, Nakamura Y, Guinard M, Klein JP, Candolfi E, Mousli M (2008) Toxoplasma gondii exploits UHRF1 and induces host cell cycle arrest at G2 to enable its proliferation. Cell Microbiol 10(4):908-920. https://doi.org/10 $.1111 / j .1462-5822.2007 .01093 . x$

29. Chang S, Shan X, Li X, Fan W, Zhang SQ, Zhang J, Jiang N, Ma D, Mao Z (2015) Toxoplasma gondii Rhoptry Protein ROP16 Mediates Partially SH-SY5Y Cells Apoptosis and Cell Cycle Arrest by Directing Ser15/37 Phosphorylation of p53. Int J Biol Sci 11(10):1215-1225. https://doi.org/10.7150/ijbs.10516

30. Hopfner R, Mousli M, Jeltsch JM, Voulgaris A, Lutz Y, Marin C, Bellocq JP, Oudet P, Bronner C (2000) ICBP90, a novel human CCAAT binding protein, involved in the regulation of topoisomerase IIalpha expression. Cancer Res 60(1):121-128

31. Gissot M, Choi SW, Thompson RF, Greally JM, Kim K (2008) Toxoplasma gondii and Cryptosporidium parvum lack detectable DNA cytosine methylation. Eukaryot Cell 7(3):537-540. https:// doi.org/10.1128/EC.00448-07

32. Pfaff AW, Georges S, Abou-Bacar A, Letscher-Bru V, Klein JP, Mousli M, Candolfi E (2005) Toxoplasma gondii regulates ICAM-1 mediated monocyte adhesion to trophoblasts. Immunol Cell Biol 83(5):483-489. https://doi.org/10.111 1/j.1440-1711.2005.01356.x

33. Halonen SK, Lyman WD, Chiu FC (1996) Growth and development of Toxoplasma gondii in human neurons and astrocytes. J Neuropathol Exp Neurol 55(11):1150-1156

34. Saeij JP, Boyle JP, Coller S, Taylor S, Sibley LD, Brooke-Powell ET, Ajioka JW, Boothroyd JC (2006) Polymorphic secreted kinases are key virulence factors in toxoplasmosis. Science 314(5806):1780-1783. https://doi.org/10.1126/science.1133690

35. Hakansson S, Charron AJ, Sibley LD (2001) Toxoplasma evacuoles: a two-step process of secretion and fusion forms the parasitophorous vacuole. EMBO J 20(12):3132-3144. https://doi. org/10.1093/emboj/20.12.3132

36. Bronner C, Trotzier MA, Filhol O, Cochet C, Rochette-Egly C, Scholler-Guinard M, Klein JP, Mousli M (2004) The antiapoptotic protein ICBP90 is a target for protein kinase 2. Ann N Y Acad Sci 1030:355-360. https://doi.org/10.1196/annals.1329.044

37. Yamaguchi L, Nishiyama A, Misaki T, Johmura Y, Ueda J, Arita K, Nagao K, Obuse C, Nakanishi M (2017) Usp7-dependent histone $\mathrm{H} 3$ deubiquitylation regulates maintenance of DNA methylation. Scientific reports 7(1):55. https://doi.org/10.1038/s4159 8-017-00136-5

38. Hervouet E, Peixoto P, Delage-Mourroux R, Boyer-Guittaut M, Cartron PF (2018) Specific or not specific recruitment of DNMTs for DNA methylation, an epigenetic dilemma. Clin Epigenetics 10:17. https://doi.org/10.1186/s13148-018-0450-y

39. Thierry S, Marechal V, Rosenzwajg M, Sabbah M, Redeuilh G, Nicolas JC, Gozlan J (2004) Cell cycle arrest in G2 induces human immunodeficiency virus type 1 transcriptional activation through histone acetylation and recruitment of CBP, NF$\mathrm{kappaB}$, and c-Jun to the long terminal repeat promoter. J Virol 78(22):12198-12206. https://doi.org/10.1128/JVI.78.22.12198 $-12206.2004$

40. Molestina RE, El-Guendy N, Sinai AP (2008) Infection with Toxoplasma gondii results in dysregulation of the host cell cycle. Cell Microbiol 10(5):1153-1165. https://doi.org/10.111 $1 / \mathrm{j} .1462-5822.2008 .01117 . \mathrm{x}$ 
41. Gold DA, Kaplan AD, Lis A, Bett GC, Rosowski EE, Cirelli KM, Bougdour A, Sidik SM, Beck JR, Lourido S, Egea PF, Bradley PJ, Hakimi MA, Rasmusson RL, Saeij JP (2015) The Toxoplasma dense granule proteins GRA17 and GRA23 mediate the movement of small molecules between the host and the parasitophorous vacuole. Cell Host Microbe 17(5):642-652. https://doi. org/10.1016/j.chom.2015.04.003

42. Alhosin M, Omran Z, Zamzami MA, Al-Malki AL, Choudhry H, Mousli M, Bronner C (2016) Signalling pathways in UHRF1dependent regulation of tumor suppressor genes in cancer. $\mathbf{J}$ Exp Clin Cancer Res 35(1):174. https://doi.org/10.1186/s1304 6-016-0453-5

43. Frauer C, Hoffmann T, Bultmann S, Casa V, Cardoso MC, Antes I, Leonhardt H (2011) Recognition of 5-hydroxymethylcytosine by the Uhrf1 SRA domain. PLoS One 6(6):e21306. https://doi. org/10.1371/journal.pone.0021306

44. Xie S, Jakoncic J, Qian C (2012) UHRF1 double tudor domain and the adjacent PHD finger act together to recognize K9me3containing histone H3 tail. J Mol Biol 415(2):318-328. https:// doi.org/10.1016/j.jmb.2011.11.012

45. Qin W, Leonhardt H, Spada F (2011) Usp7 and Uhrf1 control ubiquitination and stability of the maintenance DNA methyltransferase Dnmt1. J Cell Biochem 112(2):439-444. https://doi. org/10.1002/jcb.22998

46. Ma H, Chen H, Guo X, Wang Z, Sowa ME, Zheng L, Hu S, Zeng P, Guo R, Diao J, Lan F, Harper JW, Shi YG, Xu Y, Shi Y (2012)
M phase phosphorylation of the epigenetic regulator UHRF1 regulates its physical association with the deubiquitylase USP7 and stability. Proc Natl Acad Sci USA 109(13):4828-4833. https ://doi.org/10.1073/pnas.1116349109

47. Le Douce V, Colin L, Redel L, Cherrier T, Herbein G, Aunis D, Rohr O, Van Lint C, Schwartz C (2012) LSD1 cooperates with CTIP2 to promote HIV-1 transcriptional silencing. Nucleic Acids Res 40(5):1904-1915. https://doi.org/10.1093/nar/gkr857

48. Franco M, Panas MW, Marino ND, Lee MC, Buchholz KR, Kelly FD, Bednarski JJ, Sleckman BP, Pourmand N, Boothroyd JC (2016) A novel secreted protein, MYR1, is central to Toxoplasma's manipulation of host cells. mBio. https://doi.org/10.1128/ mbio.02231-15

49. Gomez-Diaz E, Jorda M, Peinado MA, Rivero A (2012) Epigenetics of host-pathogen interactions: the road ahead and the road behind. PLoS Pathog 8(11):e1003007. https://doi.org/10.1371/ journal.ppat. 1003007

Publisher's Note Springer Nature remains neutral with regard to jurisdictional claims in published maps and institutional affiliations. 